ORIGINAL ARTICLE

\title{
Neovascularisation and pain in jumper's knee: a prospective clinical and sonographic study in elite junior volleyball players
}

\author{
K Gisslén, H Alfredson
}

Br J Sports Med 2005;39:423-428. doi: 10.1136/bjsm.2004.013342

Background: The nature of tendon neovascularisation associated with pain over time has not been studied. Objective: To prospectively study the patellar tendons in elite junior volleyball players.

Methods: The patellar tendons in all students at the Swedish National Centre for high school volleyball were evaluated clinically and by ultrasonography (US) and Power Doppler (PD) sonography.

Results: Altogether 120 patellar tendons were followed for 7 months. At inclusion, jumper's knee was diagnosed clinically in 17 patellar tendons. There were structural changes on US in 14 tendons, in 13 of which PD sonography showed neovascularisation. There were 70 clinically normal tendons with normal US and PD sonography, 24 clinically normal tendons with abnormal US but normal PD sonography, and

See end of article for authors' affiliations ......................

Correspondence to: Dr Håkan Alfredson, Umea University, Department of Surgical and Perioperative Science, Umea 90187, Sweden; hakan.alfredson@idrott. umu.se

Accepted 20 July 2004 nine clinically normal tendons with abnormal US and neovascularisation on PD sonography. At 7 month follow up, jumper's knee was diagnosed clinically and by US in 19 patellar tendons, in 17 of which there was neovascularisation. Three of nine clinically normal tendons with structural changes and neovascularisation at inclusion developed jumper's knee. Two of 24 tendons clinically normal at inclusion, with abnormal US but normal PD sonography, developed jumper's knee with abnormal US and neovascularisation on PD sonography. A total of 20 clinically normal tendons with normal US and PD sonography at inclusion developed structural tendon changes and 12 of these also developed neovascularisation.

Conclusions: The clinical diagnosis of jumper's knee is most often associated with neovascularisation in the area with structural tendon changes. The finding of neovessels might indicate a deterioration of the condition.

J umper's knee (chronic patellar tendinosis) is a troublesome condition with unknown aetiology and pathogenesis. The condition is mainly seen in athletes engaged in explosive jumping sports, ${ }^{1-3}$ and is likely associated with overloading of the knee extensor mechanism..$^{3-8}$ Jumper's $^{\prime}$ knee is the most common overuse injury in volleyball $(28 \%)$, and $40 \%$ of professional players have experienced symptoms of jumper's knee during their careers. ${ }^{9}$

Clinically, jumper's knee is characterised by activity related pain and/or soreness at the patellar tendon attachment to the patella. ${ }^{135}{ }^{10}$ The condition is difficult to treat and there is no treatment of choice, conservative or surgical. ${ }^{11-14}$ Several studies report unpredictable results with surgical treatment. ${ }^{3}{ }^{15-19}$ Interestingly, it is not yet known where the pain comes from in this condition. ${ }^{2021}$

Ultrasonography (US) is a good method to study the tendon structure..$^{22}$ In both adolescent and adult patients with a long history of pain from the patellar tendon, examination usually shows a local widening, irregular collagen fibre structure, and hypoechogenic areas in the patellar tendon insertion into the patella. ${ }^{24}$ However, these changes can also be seen in asymptomatic athletes. ${ }^{25-27}$ Power Doppler (PD) and colour Doppler techniques can be used to study blood flow in the tendon. ${ }^{28-30}$ However, only high flow rates can be registered with these techniques as normal blood flow in the tendon does not register due to its relatively low flow rate. Recent studies on chronic painful Achilles tendon have indicated an association between pain during tendon loading activity and the occurrence of neovascularisation in the area with tendon changes. ${ }^{30} 31$

The aim of this prospective study was to clinically, and by grey scale US and PD sonography, follow the patellar tendons

in elite junior volleyball players (15-19 years) at the Swedish National Centre for volleyball during one season (30 weeks) of high intensity training and playing. We were particularly interested in the occurrence of neovascularisation and pain.

\section{METHODS}

\section{Subjects}

The most talented junior volleyball players in Sweden are recruited to the Swedish National Centre for high school volleyball. General physical tests and sport specific tests are undertaken regularly. During their 3 years at the Swedish National Centre for high school volleyball, the players consistently train and play $15 \mathrm{~h} /$ week throughout the season. Most of the volleyball players are members of the Swedish Junior National Team and participate in international tournaments. Four teams represent the high school in the Swedish Volleyball Federation leagues, from the women's top elite division to the first and second divisions for men and women.

After permission from the Educational Board of the Swedish National Centre for volleyball, all 60 players (29 male and 31 female) in first, second, and third grades (1519 years old) were invited to participate in the study.

The study was approved by the Ethical Committee of the Medical Faculty at the University of Gothenburg, Sweden. All volleyball players provided written informed consent.

The study started at the beginning of the semester in September 2002 with a lecture on jumper's knee (patellar tendinosis) for all students. Thereafter, all students filled out a questionnaire (see below) with investigator (KG) assistance.

Abbreviations: PD, power Doppler; US, ultrasonography 
Table 1 Volleyball players $(n=60)$ basic data at baseline

\begin{tabular}{|c|c|c|c|c|c|c|}
\hline \multirow[b]{2}{*}{ Variable } & \multicolumn{2}{|l|}{ Grade 1} & \multicolumn{2}{|l|}{ Grade 2} & \multicolumn{2}{|l|}{ Grade 3} \\
\hline & Male $(n=11)$ & Female $(n=11)$ & Male $(n=8)$ & Female $(n=8)$ & Male $(n=10)$ & Female $(n=12)$ \\
\hline Age (years) & $16.3(0.4)$ & $16.1(0.6)$ & $17.0(0.7)$ & $17.1(0.5)$ & $18.5(0.4)$ & $17.9(0.6)$ \\
\hline Height $(\mathrm{cm})$ & $190(6)$ & $174(4)$ & $187(6)$ & $178(3)$ & $184(7)$ & $174(7)$ \\
\hline Weight $(\mathrm{kg})$ & $80.6(12.1)$ & $65.9(5.7)$ & $77.6(9.6)$ & $67.7(7.2)$ & $79.5(8.5)$ & $68.6(7.8)$ \\
\hline Volleyball played (years) & $3.7(2.5)$ & $4.1(1.4)$ & $4.6(2.8)$ & $4.1(2.0)$ & $7.2(2.3)$ & $6.2(1.7)$ \\
\hline
\end{tabular}

\section{Questionnaire and clinical examination}

Questions to the athletes included: date of birth, amount and type of training, present and former symptoms involving the patellar tendon, treatments, other knee injuries, and results of treatments. The volleyball players who reported pain at the patellar tendon marked the area of pain on a special knee chart.

All participants underwent a clinical knee examination by a registered sports physiotherapist (KG). The examination included palpation of the patellar tendon, in particular its attachment to the inferior pole of the patella. Tests that aimed to reproduce the pain of patellar tendinosis included: one leg body weighted squats and drop jumps (plyometric jump) on each leg from $20 \mathrm{~cm}$ and/or $43 \mathrm{~cm}$. Clinical tests to exclude differential diagnoses were also performed.

The following diagnostic criteria for jumper's knee were used: history ( $>4$ weeks) of exercise/volleyball associated pain at the patellar tendon insertion into the inferior pole of the patella, ${ }^{1}$ tenderness to palpation, ${ }^{1}{ }^{32}$ and pain during provocative tests of the knee extensors. ${ }^{53} 34$

\section{Sonography}

A single experienced musculoskeletal radiologist, who was blinded to the volleyball player's clinical history, performed all US and PD examinations. A high resolution linear array $8 \mathrm{MHz}$ ultrasound transducer (Sequoia 512, Acuson, Mountain View, CA) was used for all examinations.

\section{Grey scale US}

US was performed using longitudinal and transverse grey scale scans of the left and right patellar tendons with the patient lying supine and the knees in extension. The thickness of the tendon was measured and structural changes (hypoechoic areas) evident in both the longitudinal and the transverse scans were recorded.

\section{PD examination}

PD sonography was used to study blood flow in the patellar tendon. As only high flows can be registered, the technique does not allow for registration of the normal circulation in the tendon because of the relatively low flow rate.

To our knowledge, there is no method to quantify blood flow in the tendon. Therefore, we used a semi-quantitative scale as follows: 0 , no flow; 1 , flow outside the tendon; 2 , one or two vessels inside the tendon; and 3, multiple vessels inside the tendon.

For analysis, only those tendons with vessels inside the tendon were considered to have neovascularisation.

\section{Statistical methods}

The results are presented as means (SD) and were analysed with Excel 2000 (Microsoft, Redmond, WA, USA).

\section{RESULTS}

\section{Subject characteristics}

All 60 volleyball players, 29 males (48\%) and 31 females $(52 \%)$, studying at The Swedish National Centre of high school volleyball participated in the study. Of these 60 players (120 tendons), one player had previously been treated with steroid injections and had later been surgically treated bilaterally for jumper's knee (patellar tendinosis) and one player had previously been treated with steroid injections in one tendon. The surgical treatment and the treatment with steroid injections were carried 9 months before the study started. These two players were included in the study. Descriptive data on the subjects are presented in table 1. All results are presented as numbers of tendons (not number of individuals).

\section{At baseline}

A clinical diagnosis of jumper's knee was made in 17 patellar tendons ( 10 male and seven female), 14 of which also had structural changes on US. In 13 ( 10 male and three female) of these 14 tendons, PD sonography showed neovascularisation within the area of structural changes on US (figs 1 and 2; tables 2 and 3). A total of 70 tendons ( 32 male and 38 female) were clinically normal, had normal US, and had no neovascularisation on PD sonography. However, 24 clinically normal tendons (nine male and 15 female) had abnormal US but had no neovascularisation on PD sonography, while nine clinically normal tendons (seven male and two female) had abnormal US and neovascularisation on PD sonography. Three tendons (three female) positive for a clinical diagnosis of jumper's knee had a normal US and no neovascularisation on PD sonography.

\section{At 7 month follow up}

A clinical diagnosis of jumper's knee was made in 19 tendons ( 13 male and six female). In 17 (13 male and four female) of

Table 2 Jumper's knee in volleyball players $(n=60)$ at baseline and at 7 month follow up

\begin{tabular}{|c|c|c|c|c|c|c|c|c|c|c|c|c|}
\hline & \multicolumn{4}{|l|}{ Grade 1} & \multicolumn{4}{|c|}{ Grade 2} & \multicolumn{4}{|l|}{ Grade 3} \\
\hline & \multicolumn{2}{|l|}{ Baseline } & \multicolumn{2}{|c|}{ Follow up } & \multicolumn{2}{|l|}{ Baseline } & \multicolumn{2}{|c|}{ Follow up } & \multicolumn{2}{|l|}{ Baseline } & \multicolumn{2}{|c|}{ Follow up } \\
\hline & $\begin{array}{l}\text { Male } \\
(n=22)\end{array}$ & $\begin{array}{l}\text { Female } \\
(n=22)\end{array}$ & $\begin{array}{l}\text { Male } \\
(n=22)\end{array}$ & $\begin{array}{l}\text { Female } \\
(n=22)\end{array}$ & $\begin{array}{l}\text { Male } \\
(n=16)\end{array}$ & $\begin{array}{l}\text { Female } \\
(n=16)\end{array}$ & $\begin{array}{l}\text { Male } \\
(n=16)\end{array}$ & $\begin{array}{l}\text { Female } \\
(n=16)\end{array}$ & $\begin{array}{l}\text { Male } \\
(n=20)\end{array}$ & $\begin{array}{l}\text { Female } \\
(n=24)\end{array}$ & $\begin{array}{l}\text { Male } \\
(n=20)\end{array}$ & $\begin{array}{l}\text { Female } \\
(n=24)\end{array}$ \\
\hline Jumper's knee & 4 & 4 & 6 & 5 & 2 & 0 & 3 & 0 & 4 & 3 & 4 & 1 \\
\hline
\end{tabular}




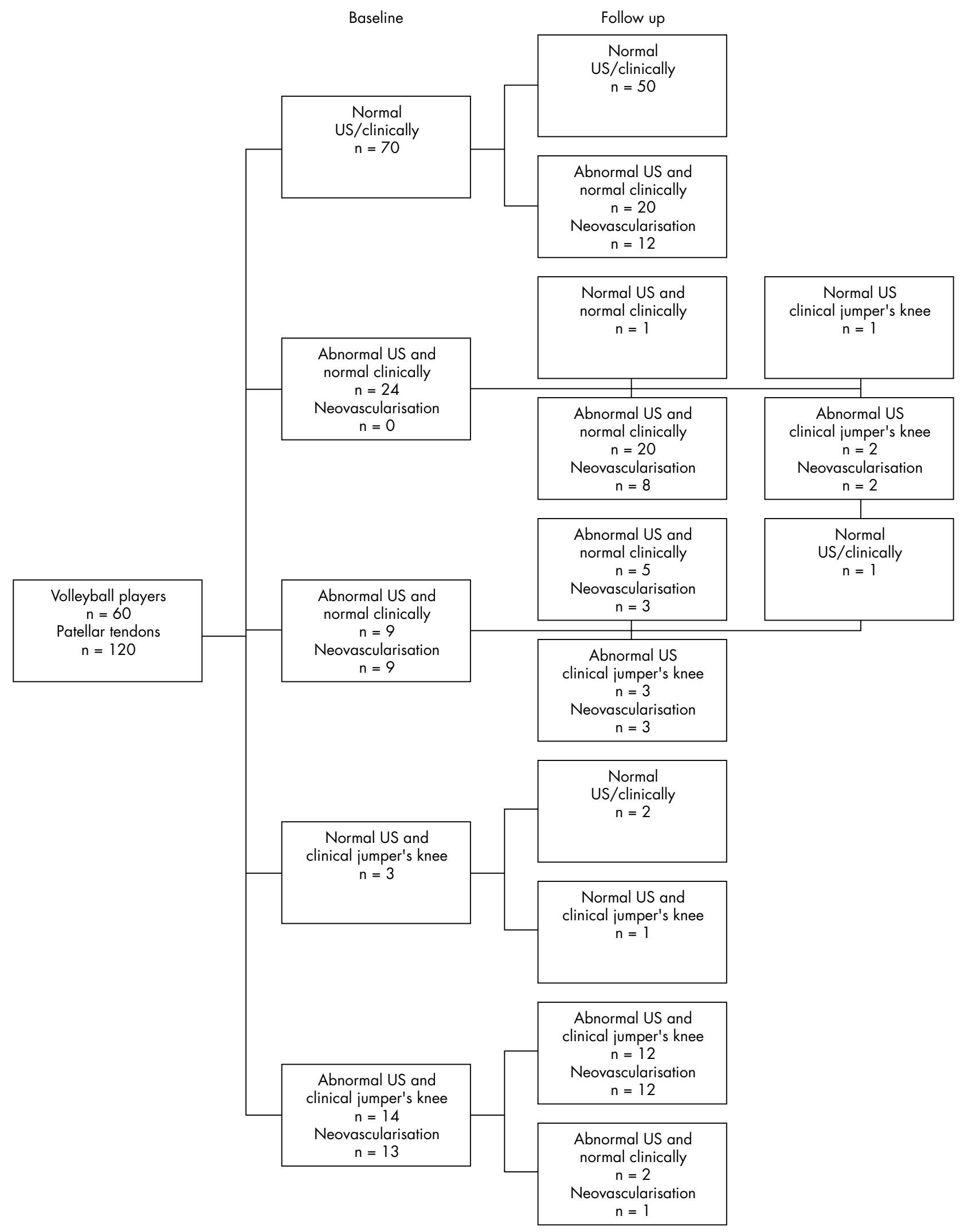

Figure 1 Flow chart summarising the longitudinal outcomes.

these there were also structural tendon changes on US and neovascularisation on PD sonography (fig 1; tables 2 and 3).

During the 7 month period of observation, three (two male and one female) of the nine asymptomatic tendons with structural changes and neovascularisation at inclusion developed clinical symptoms of jumper's knee, and had abnormal US and neovascularisation on PD sonography. Of the remaining six tendons in this category at inclusion, three 
Table 3 Jumper's knee symptoms and sonographic findings at baseline and at 7 month follow up

\begin{tabular}{|c|c|c|c|c|c|c|c|c|c|}
\hline & \multicolumn{5}{|c|}{ Chronic symptomatic tendons } & \multicolumn{4}{|c|}{ Asymptomatic tendons } \\
\hline & \multicolumn{2}{|c|}{ Baseline } & \multicolumn{3}{|c|}{ Follow up } & \multicolumn{2}{|c|}{ Baseline } & \multicolumn{2}{|c|}{ Follow up } \\
\hline & Male & Female & Male & & Female & Male & Female & Male & Female \\
\hline Hypoechoic regions & 0 & 1 & 0 & & 0 & 2 & 8 & 5 & 11 \\
\hline Hypoechoic regions and PD flow 1 & 0 & 0 & 0 & & 0 & 7 & 7 & 5 & 2 \\
\hline Hypoechoic regions and PD flow 2-3 & 10 & 3 & 13 & & 4 & 7 & 2 & 17 & 7 \\
\hline No changes on US & 0 & 3 & 0 & & 2 & 32 & 38 & 18 & 36 \\
\hline Total & \multicolumn{2}{|c|}{17} & \multicolumn{3}{|c|}{19} & \multicolumn{2}{|c|}{103} & \multicolumn{2}{|c|}{101} \\
\hline
\end{tabular}

tendons (three male) did not change in any respect, in two tendons (two male) the neovascularisation disappeared on PD sonography, and in one tendon (one female) the US normalised (that is, vessels also disappeared).

Two of 24 clinically normal tendons (one male and one female) which had abnormal US but no neovascularisation on PD sonography at inclusion, developed clinical jumper's knee, together with abnormal US and neovascularisation on PD sonography.

A total of 20 pain free and ultrasonographically normal tendons developed structural tendon changes on US, and 12 of these (nine male and three female) also developed neovascularisation on PD sonography.

At inclusion, three tendons (three female) were diagnosed clinically as having jumper's knee but had normal US and no neovascularisation on PD sonography. At follow up, two of these were now clinically normal and still had normal US and no neovascularisation on PD sonography. The other was still diagnosed as jumper's knee, but had normal US and no neovascularisation on PD sonography.

\section{DISCUSSION}

This longitudinal study provides novel cross sectional and longitudinal data regarding structural changes on US, neovessels seen on PD sonography, and clinical correlation in jumper's knee.

\section{Prevalence and structural abnormality on US}

Jumper's knee is a common problem among senior volleyball players." This investigation shows that jumper's knee is already relatively common (14\%) among high level volleyball players at a relatively young age. This is higher than the $7 \%$ Cook et al reported in a group of male and female basketball players (14-18 years of age), ${ }^{2}$ but lower than the 36\% reported by Lian et al in a group of 47 male senior professional volleyball players. ${ }^{27}$

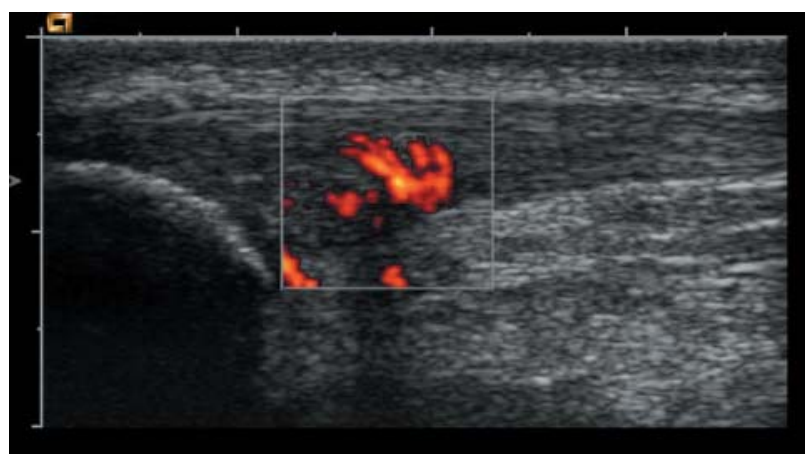

Figure 2 Longitudinal scan of the patellar tendon. The hypoechic region and neovascularisation is seen in the marked area. PD signals indicate flow inside the tendon and its immediate surroundings.
The absence of an association between structural tendon changes and symptoms of jumper's knee has previously been reported..$^{19} 2627$ In our study, we found grey scale structural tendon changes at baseline, but no pain, in 33/120 tendons $(28 \%)$. Neovessels as seen on PD sonography, however, had a $59 \%$ correct association with pain (13 painful of 22 with neovessels). At follow up, there were structural tendon changes, but no pain, in 47/120 tendons (39\%). Cook et al found structural changes, but no pain, in 56/268 (21\%) patellar tendons in a similar group of junior basketball players. $^{2}$

The results are comparable with those in a group of asymptomatic male elite soccer players, where structural changes were present in 18/98 tendons ( $18 \%$ ) at baseline and in 15/98 tendons (15\%) at follow up. ${ }^{35}$ In 3/18 tendons with persistent structural tendon changes, symptoms characterised as jumper's knee had developed. ${ }^{35}$

\section{Association between neovessels and tendon pain}

The possible relationship between chronic tendon pain and neovascularisation has recently been highlighted in the Achilles tendon. In patients with chronic painful mid-portion Achilles tendinosis ${ }^{3031}$ and chronic insertional Achilles tendon pain, ${ }^{36}$ we demonstrated an association between the occurrence of neovascularisation and pain during tendon loading activity. Also, Terslev et $a^{28}$ reported an association between neovessels and pain in a small sample of elite male basketball players with jumper's knee. In the present study, the majority of patients, especially the males, who had a clinical diagnosis of jumper's knee also had structural tendon changes and neovascularisation. These findings indicate a possible relationship between the combination of structural tendon changes plus neovascularisation, and pain during patellar tendon loading activity. It is noteworthy that at inclusion there were nine clinically normal tendons that had structural tendon changes plus neovascularisation, but no pain. Interestingly, during the 7 months of observation, three out of these nine tendons developed clinical jumper's knee. This is a high proportion (33\%), possibly indicating that it could be worth screening this at risk population. Furthermore, in 12 out of the 70 tendons that were normal at inclusion, structural tendon changes and neovascularisation developed during the follow up period. This was not associated with pain at that time, but further longitudinal follow up is warranted.

In the present study, it was interesting to notice that during the 7 month period of high intensity training and volleyball playing, structural tendon changes and neovascularisation developed in 12 tendons. Almost all of these tendons belonged to individuals in the second and third grades (11/12) where there is more specific and heavier weight training, and a higher intensity and frequency of volleyball training compared to first grade. Altogether, most of the tendons with structural tendon changes belonged to individuals in grades two and three. This is in accordance 


\section{What is already known on this topic}

Jumper's knee (chronic patellar tendinosis) is a troublesome condition mainly seen in athletes engaged in explosive jumping sports, such as volleyball, and is likely associated with overloading of the knee extensor mechanism.

with the findings reported by Cook et al in a similar group of junior basketball players. ${ }^{2}$ Structural tendon changes have previously been suggested to increase the risk of developing symptoms of jumper's knee in junior basketball players. ${ }^{37}$

The correlation between the occurrence of neovessels and pain is moderate in this study but better than that found using grey scale US alone in the cross sectional analysis. However, this is a prospective study, and perhaps neovessels are early signs of a deterioration of the condition, in later stages resulting in pain during tendon loading activity. Further studies should examine whether vascular effects (ingrowth, dilatation) precede neural changes (ingrowth, stimulation) in this condition. Further follow up studies will clarify the fate of these tendons.

In summary, a clinical diagnosis of jumper's knee in junior elite volleyball players is associated with neovascularisation in the area with structural tendon changes, and neovascularisation together with structural tendon changes in asymptomatic volleyball players may indicate a risk for developing jumper's knee. Further prospective studies over a longer period of time can possibly clarify the dynamic patterns between the development of clinical symptoms and structural and vasculoneural tendon changes.

\section{Authors' affiliations}

K Gisslén, H Alfredson, Department of Surgical and Perioperative Science, Sports Medicine, University of Umeå, Umeå, Sweden

Competing interests: none declared.

\section{REFERENCES}

1 Blazina ME, Kerlan RK, Jobe FW, et al. Jumper's knee. Orthop Clin North Am 1973;4(3):665-78.

2 Cook JL, Khan KM, Kiss ZS, et al. Patellar tendinopathy in junior basketball players: a controlled clinical and ultrasonographic study of 268 patellar tendons in players aged 14-18 years. Scand J Med Sci Sports 2000;10:216-20

3 Ferretti A, Puddu G, Mariani PP, et al. The natural history of jumper's knee. Patellar or quadriceps tendonitis. Int Orthop 1985;8(49):239-42.

4 Kujala UM, Aalto T, Österman K, et al. The effect of volleyball playing on the extensor mechanism. Am J Sports Med 1989;10(4):295-8.

5 Lian Ø, Engebretsen L, Øvrebø R, et al. Characteristics of the leg extensors in male volleyball players with jumper's knee. Am J Sports Med 1996;24(3):380-5.

6 Richards DP, Ajemian SV, Wiley JP, et al. Knee joint dynamics predict patellar tendinitis in elite volleyball players. Am J Sports Med 1996;24(5):676-83.

7 Lian Ø, Refsnes P-E, Engebretsen L, et al. Performance characteristics of volleyball players with patellar tendinopathy. Am I Sports Med 2003;31(3):408-13

8 Roels J, Martens M, Mulier JC, et al. Patellar tendinitis (jumper's knee). Am J Sports Med 1978;6(6):362-8.

9 Ferretti A. Epidemiology of jumper's knee. Sports Med 1986;3:289-95.

10 Khan KM, Maffulli N, Coleman BD, et al. Patellar tendinopathy: some aspects of basic science and clinical management. Br J Sports Med 1998:32:346-55

11 Cook JL, Khan KM, Harcourt PR, et al. A cross sectional study of 100 athletes with jumper's knee managed conservatively and surgically. Br J Sports Med 1997;31:332-6.

12 Cook JL. What is the appropriate treatment for patellar tendinopathy? Br J Sports Med 2001;35(5):291-4.

13 Kettunen JA, Kvist MK, Alanen E, et al. Long-term prognosis for Jumper's knee in male athletes: a prospective follow-up study. Am J Sports Med 2002;30(5):689-92

14 Torstensen ET, Bray RC, Wiley JP. Patellar tendinitis: a review of current concepts and treatment. Clin J Sport Med 1994;4:77-82.
What this study adds

Neovascularisation was a common finding in adolescent elite junior volleyball players with a clinical diagnosis of jumper's knee combined with structural tendon changes at ultrasonography. The occurrence of neovessels might possibly indicate a deterioration of the condition.

15 Coleman BD, Khan KM, Kiss ZS, et al. Open and arthroscopic patellar tenotomy for chronic patellar tendinopathy. A retrospective outcome study. Victorian Institute of Sport Tendon Study Group. Am J Sports Med 2000;28(2): 183-90

16 Coleman BD, Khan KM, Maffulli N, et al. Studies of surgical outcome after patellar tendinopathy: clinical significance of methodological deficiencies and guidelines for future studies. Scand J Med Sci Sports 2000;10:2-11

17 Ferretti A, Ippolito E, Mariani P, et al. Jumper's knee. Am J Sports Med 1983;11(2):58-62.

18 Karlsson J, Kälebo P, Goksör L-E, et al. Partial rupture of the patellar ligament. Am J Sports Med 1992;20(4):390-5.

19 Khan KM, Visentini PJ, Kiss ZS, et al. Correlation of ultrasound and magnetic resonance imaging with clinical outcome after patellar tenotomy: prospective and retrospective studies. Clin J Sport Med 1999;9:129-37.

20 Khan KM, Cook JL, Maffulli N, et al. Where is the pain coming from in tendinopathy? It may be biochemical, not only structural, in origin. $\mathrm{Br} J$ Sports Med 2000;34(2):81-3.

21 Alfredson $\mathrm{H}$, Forsgren $\mathrm{S}$, Thorsen $\mathrm{K}$, et al. In vivo microdialysis and immunohistochemical analyses of tendon tissue demonstrated high amounts of free glutamate and glutamate NMDR1 receptors, but no signs of inflammation, in Jumper's knee. J Orthop Res 2001;19:881-6.

22 Paavola M, Paakkala T, Kannus $P$, et al. Ultrasonography in the differential diagnosis of Achilles tendon injuries and related disorders. Acta Radiol 1998;39:612-9.

23 Åström M, Gentz CF, Nilsson P, et al. Imaging in chronic Achilles tendinopathy: a comparison of ultrasonography, magnetic resonance imaging and surgical findings in 27 histologically verified cases. Skeletal Radiol 1996;25:615-20.

24 Khan KM, Bonar F, Desmond PM, et al. Patellar tendinosis (Jumper's knee) findings at histopathologic examination, US and MR imaging. Radiology 1996;200:821-7

25 Cook JL, Khan KM, Kiss ZS, et al. Asymptomatic hypoechoic regions on patellar tendon ultrasound: a 4-year clinical and ultrasound follow up of 46 tendons. Scand J Med Sci Sports 2001;11:321-7.

26 Khan KM, Cook JL, Kiss ZS, et al. Patellar tendon ultrasonography and Jumper's knee in female basketball players: a longitudinal study. Clin J Sport Med 1997;7:199-206.

27 Lian $\varnothing$, Holen KJ, Engebretsen L, et al. Relationship between symptoms of jumper's knee and the ultrasound characteristics of the patellar tendon among high level male volleyball players. Scand J Med Sci Sport 1996;6:291-6.

28 Terslev L, Qvistgaard E, Torp-Pedersen S, et al. Ultrasound and power Doppler findings in jumper's knee - preliminary observations. Eur J Ultrasound 2001;13:183-9.

29 Weinberg EP, Adams MJ, Hollenberg GM. Color Doppler sonography of patellar tendinosis. AJR 1998;171(3):743-4.

30 Öberg L, Lorentzon R, Alfredson $\mathrm{H}$. Neovascularisation in Achilles tendons with painful tendinosis but not in normal tendons: an ultrasonographic investigation. Knee Surg Sports Traumatol Arthrosc $2001 ; 9: 233-8$

31 Alfredson $\mathrm{H}$, Öberg L, Forsgren $\mathrm{S}$. Is vasculo-neural ingrowth the cause of pain in Achilles tendinosis? An investigation using ultrasonography and colour Doppler, immunohistochemistry, and diagnostic injections. Knee Surg Sports Traumatol Arthrosc 2003;11:334-8.

32 Cook JL, Khan KM, Kiss ZS, et al. Reproducibility and clinical utility of tendon palpation to detect patellar tendinopathy in young basketball players. Br J Sports Med 2001;35:65-9.

33 Stanish WD, Rubinovich RM, Curwin S. Eccentric exercise in chronic tendinitis. Clin Orthop 1986;208:65-8.

34 Bobbert MF, Huijing PA, Van Ingen Schnau GJ. Drop jumping. II. The influence of dropping height on the biomechanics of drop jumping. Med Sci Sports Exerc 1987; 19(4):339-46.

35 Fredberg U, Bolvig L. Significance of ultrasonographically detected asymptomatic tendinosis in the patellar and achilles tendons of elite soccer players. Am J Sports Med 2002;30(4):488-91

36 Öberg L, Alfredson H. Sclerosing therapy in chronic Achilles tendon insertional pain - results of a pilot study. Knee Surg Sports Traumatol Arthrosc 2003;11:339-43.

37 Cook JL, Khan KM, Kiss ZS, et al. Prospective imaging study of asymptomatic patellar tendinopathy in elite junior basketball players. J Ultrasound Med 2000;19:473-9. 
This clinical paper deals with the most intriguing matter of overuse related tendon changes in athletes. This study may in particular facilitate the search for the missing link between structural changes and symptoms. ${ }^{12}$ The association of neovascularisation and symptoms (or increased risk for symptoms) supports earlier mentioned hypotheses of neural ingrowth accompanying neovessels and possibly causing pain in tendinopathy. ${ }^{3}$ The idea, suggested by the authors, that neovascularisation reflects a deterioration of the condition was also mentioned in connection with Achilles tendinopathy. ${ }^{4}$ However, whether the vascular ingrowth precedes the neural ingrowth in tendinopathy is thus far not substantiated and warrants further studies on this subject. Moreover, a notable observation is the existence of clinical tendinopathy without ultrasonographic changes or neovascularisation. This type of patients would not fit in the suggested pattern of symptoms and vasculoneural tendon changes. Nevertheless, much credit must be given to this very interesting clinical study that undeniably will prompt further research on tendinopathy.

\section{REFERENCES}

1 Khan KM, Cook JL, Maffulli N, et al. Where is the pain coming from in tendinopathy? It may be biochemical, not only structural, in origin. $\mathrm{Br} J$ Sports Med 2000;34:81-3

2 Khan KM, Cook JL. Overuse tendon injuries: where does the pain come from? Sports Med Arthrosc Rev 2000;8:17-31.

3 Alfredson $\mathbf{H}$, Ohberg L, Forsgren S. Is vasculo-neural ingrowth the cause of pain in chronic Achilles tendinosis? An investigation using ultrasonography and colour Doppler, immunohistochemistry, and diagnostic injections. Knee Surg Sports Traumatol Arthrosc 2003;11:334-8.

4 Peers KH, Brys PP, Lysens RJ. Correlation between power Doppler ultrasonography and clinical severity in Achilles tendinopathy. Int Orthop 2003;27:180-3.

\section{ELECTRONIC PAGES}

\section{Online case reports}

7 he following electronic only articles are published in conjunction with this issue of BJSM

\section{Sequential avulsion of the anterior inferior iliac spine} in an adolescent long jumper

\section{Yildiz, Y Yildiz, M T Ozdemir, et al}

We present here an unusual case of a sequential avulsion fracture of the anterior inferior iliac spine (AIIS), occurring first in the right and then the left AIIS, during long jump attempts. The case of a 17 year old boy with pain around his right groin, which first occurred during a long jump attempt, is presented. Radiographic examination revealed an avulsion fracture of the right AIIS. After conservative treatment, full athletic activity was allowed 2 months after the injury. However, 4 months later the patient returned with a similar pain in the opposite side of his groin. Radiographs revealed another fracture of the left AIIS. The boy underwent the same treatment protocol; he was examined with isokinetic dynamometry. No complication or re-injury occurred during the 2 year follow up period. In the present study, we introduce the first case of a sequential bilateral AIIS avulsion fracture caused by a long jump.
(Br J Sports Med 2005;39:e31) http://bjsm.bmjjournals.com/ cgi/content/full/39/7/e31

\section{Ventricular septal defect in a world class runner A Boraita, J Esteve-Lanao, M Perez, et al}

We report the case of an elite male, East African endurance runner ( 18 years old) who ranked in the top 15 in the World Cross Country Championships (sub 21 year old category) despite having a ventricular septal defect (VSD; width: 0.22 $\mathrm{cm}$ ) that was diagnosed 2 weeks after this event with echocardiographic evaluation. This athlete was a moderate altitude native $(\sim 3000 \mathrm{~m})$. Cardiac dimensions were within normal limits and no significant pathological signs were observed. His $\mathrm{Vo}_{2 \max }$ was relatively low given his performance level $\left(67.9 \mathrm{ml} \mathrm{kg}^{-1} \mathrm{~min}^{-1}\right)$. Despite his limited training background (only l year), his running economy was, however, better than the values reported in our laboratory for Caucasian runners of the same age. Further cardiological follow up might confirm that the VSD causes no pathological effects or any performance detriment in future years.

(Br J Sports Med 2005;39:e32) http://bjsm.bmjjournals.com/ cgi/content/full/39/7/e32 